\title{
BM] Global Health Learning for Universal Health Coverage
}

To cite: Meessen B, Akhnif ELH, Kiendrébéogo JA, et al. Learning for Universal Health Coverage. BMJ Global Health 2019;4:e002059. doi:10.1136/ bmjgh-2019-002059

Handling editor Seye Abimbola

Received 7 October 2019 Revised 15 November 2019 Accepted 17 November 2019

\section{Check for updates}

(c) Author(s) (or their employer(s)) 2019. Re-use permitted under CC BY-NC. No commercial re-use. See rights and permissions. Published by BMJ.

For numbered affiliations see end of article.

Correspondence to

Bruno Meessen;

bmeessen@thecollectivity.org

Bruno Meessen (D) , ${ }^{1}$ EL Houcine Akhnif, ${ }^{2}$ Joël Arthur Kiendrébéogo, ${ }^{3,4,5}$ Abdelali Belghiti Alaoui, ${ }^{6,7}$ Kefilath Bello, ${ }^{5,8}$ Sanghita Bhattacharyya, ${ }^{9,10}$ Hannah Sarah Faich Dini, ${ }^{11}$ Fahdi Dkhimi, ${ }^{12}$ Jean-Paul Dossou (i) , 5 Allison Gamble Kelley, ${ }^{13}$ Basile Keugoung, ${ }^{14}$ Tamba Mina Millimouno, ${ }^{15}$ Jérôme Pfaffmann Zambruni, ${ }^{11}$ Maxime Rouve, ${ }^{5}$ Isidore Sieleunou, ${ }^{16,17}$ Godelieve van Heteren ${ }^{18}$

\section{ABSTRACT}

The journey to universal health coverage (UHC) is full of challenges, which to a great extent are specific to each country. 'Learning for UHC' is a central component of countries' health system strengthening agendas. Our group has been engaged for a decade in facilitating collective learning for UHC through a range of modalities at global, regional and national levels. We present some of our experience and draw lessons for countries and international actors interested in strengthening national systemic learning capacities for UHC. The main lesson is that with appropriate collective intelligence processes, digital tools and facilitation capacities, countries and international agencies can mobilise the many actors with knowledge relevant to the design, implementation and evaluation of UHC policies. However, really building learning health systems will take more time and commitment. Each country will have to invest substantively in developing its specific learning systemic capacities, with an active programme of work addressing supportive leadership, organisational culture and knowledge management processes.

\section{INTRODUCTION}

The last United Nations General Assembly, in September 2019, confirms that universal health coverage (UHC) will remain high on the global agenda. ${ }^{1}$ The journey to UHC, however, is complex, notably at country levels. International agencies and experts can provide assistance, but the real challenges are to a great extent specific to each country, with its unique health system and political context. Thus, each country will have to find its own way and develop systemic learning capacities for UHC, which may refer to the set of capacities across interconnected actors to learn from action (their own and others') to progress towards UHC. We contend that the operational and research agendas for building such capacities at country level are still underdeveloped, despite the growing recognition of their importance to health system strengthening and UHC.
Summary box

Many low-income and middle-income countries are keen to build their systemic learning capacities to progress towards universal health coverage.

- Some lessons from transnational learning programmes have relevance for action at country level.

- Overall, granting a much more central role to 'learning' in health system strengthening efforts is crucial.

- In that process, we must acknowledge that the arena of relevant knowledge holders is much wider than the established circles of researchers and international experts alone. Opportunities for learning abound. Knowledge exists in many forms.

- A significant effort is needed to encourage health authorities and academia to embrace a vision to learning more anchored into practice. A cultural shift is also needed at the level of health administrations.

We would like to invite ministries of health, their national and international partners and academia to embrace a new perspective on learning. Over the last decades, learning has rarely been treated as a real priority for many reasons. In some countries, national capacities were affected by budget cuts. In others, actors often hold a particularly unidirectional view of learning, as a game of 'knowers' (academics, technical assistants, aid experts, senior officials) and so-called 'learners' (everybody else). Schools of public health and scientific journals have been cast as the main receptacles of knowledge. And courses, trainings and workshops are proposed as the regular 'mode' for the implementation of any new strategies or practices in health programme.

This familiar configuration of the 'learning arena' is now increasingly being challenged. More contemporary views on learning have come to the fore. They present learning as a social process: we learn through our embeddedness in communities of peer practitioners. ${ }^{2}$ Of course, updates of knowledge and 
beliefs remain key, but action and behavioural changes get increasing attention. ${ }^{3}$ Start-up industries have helped to promote some of these alternative approaches to learning, putting full attention on iterative testing and improvement informed by rapid analysis of emerging information from user experience. ${ }^{4}$

This growing recognition of the need for new approaches and a larger set of methods has rubbed off on the international community. For almost 10 years, our own group has been engaged in facilitating 'collective learning for UHC' through a range of modalities, with some success. ${ }^{5}$ In this article, we share some of our practices, from local to global levels, and wish to draw a number of lessons for countries and international actors interested in strengthening national systemic learning capacities for UHC.

\section{OUR PRACTICE IN COLLECTIVE LEARNING Kickstarting communities of practice}

Nine years ago, a multi-country study revealed how in many low-income countries (LICs), user fee removal policies were fraught with implementation shortcomings. ${ }^{6}$ In an opinion piece, some of us called for more attention to be paid to the knowledge needs of implementation actors, and advocated for the setting up of transnational communities of practice $(\mathrm{CoPs}){ }^{7}$ The proposition at the time was to gather some key stakeholders (eg, policymakers, practitioners, researchers) around a specific area of interest, to share and co-produce relevant knowledge in order to strengthen implementation.

Subsequently, we proceeded to establish and facilitate a number of such CoPs, covering broad domains such as financial access to health services, performance-based financing $(\mathrm{PBF})$, health service delivery, community health and governance. In the process, we gathered thousands of experts in online discussion fora. From the start, we aimed to make these CoPs much more than just online communities. We organised face-to-face meetings and workshops, ${ }^{8}$ conducted multi-country research, ${ }^{9-11}$ developed frameworks and training modules, ${ }^{12}$ broadcast webinars, organised a cartoon contest and carried out a range of other collaborative activities.

\section{From knowledge management to collective intelligence, via digital platforms}

Working with CoPs greatly stimulated and grew our understanding of the knowledge needs of countries and of individual experts. We moved rapidly beyond merely diffusing and sharing knowledge. Increasingly, developing continuous learning together with CoP members, became the centre of activity. This resulted in a growing realisation that such approaches could also be relevant for action at country level.

A major source of inspiration at that stage was the concept of 'learning organisation' (LO), put forward by experts in organisational studies. ${ }^{13}$ This concept stresses that learning is a strategic practice for organisations to thrive and create value in rapidly changing environments. The notion of 'LO' progressively inspired our CoP members and informed their actions. This became manifest in a lot of the CoPs' activities.

For instance, participants of a regional conference co-organised by the Health Service Delivery CoP recommended that health district management teams transform their health districts into LO ${ }^{8}$ Action-research was developed in Benin and Guinea as one example of follow-up. The research pertained to testing the feasibility of a facilitated learning process combining, on one digital platform (district.team), data visualisation and explanatory peer-to-peer discussion across health district teams in the country. Data visualisation and discussions were on topics relevant for district operations: outbreak preparedness, maternal death surveillance, PBF, etc. To improve our intervention, we put ourselves in a learning mode. Some key principles of the start-up industry were introduced ${ }^{4}$ : such as putting one's focus on just a few hypotheses, using a simplified digital solution to test them, introduce active monitoring and rapid identification and adoption of emerging lessons. The collective intelligence strategy applied to 'hard data' - tested under district.teamproved to be particularly effective ${ }^{14}$ and popular among district managers. At the same time, it did also highlight that transforming health administrations into LO necessitates proper time and commitment. ${ }^{15}$

In another follow-up to a regional workshop in Bujumbura (Burundi), experts from two CoPs decided to document the fragmentation of health financing in Francophone Africa. One of their main findings was the absence, in each of the 12 countries studied, of a coherent overview of health financing schemes in place. ${ }^{9}$ Such an information deficit is problematic, especially since UHC financing tends to be built out from existing schemes, not from scratch. So finding this deficit led CoP experts to yet another participatory study, focused on systemic learning capacities for UHC in six countries. ${ }^{11}$ It demonstrated that in these countries, 'UHC systems' were not yet full learning systems. Experts identified several basic weaknesses: in the level of leadership (not supportive enough to learning), in the organisational culture (not fully adapted to learning) and in knowledge management processes (under-developed).

Across our activities, learning for UHC has emerged as an important collective undertaking. Working as a community has enabled interpersonal relationships and trust to flourish, which are pivotal for learning. Over the years, we have seen the importance of developing interactive digital platforms to connect beyond face-to-face encounters. Much of our initial focus has been on the needs of practitioners, who are too often forgotten by the global health community. ${ }^{7}$ Besides online discussion groups, blogs (http://www.healthfinancingafrica.org/), webinars and the district.team platforms, we have developed The Collectivity (https://www.thecollectivity.org/), a new collaborative platform for practitioners willing to work together in global health. We see co-production as a 
central condition for ownership and further application of the learning that emerges.

\section{LESSONS FOR COUNTRIES AND THE GLOBAL HEALTH COMMUNITY}

A decade of activities in such learning practices has confirmed the relevance and importance of investing in 'collective intelligence', defined in Wikipedia (possibly, the paragon of the concept) as 'shared or group intelligence that emerges from the collaboration, collective efforts, and competition of many individuals and appears in consensus decision making'. ${ }^{16}$ These activities have brought home a series of core lessons for advancing UHC. We believe they have relevance for countries beyond transnational situations.

\section{Develop learning agendas}

The facilitation of CoPs has taught us the importance of organising our collective learning around learning agendas. By a 'learning agenda' we mean: a collective, reasoned, adaptive and sustained practice of identifying the questions that require a response and of implementing strategies to answer these questions (through analysis of routine data, consultation, deliberation, research, etc). For instance, in our work within the PBF CoP, we have progressively realised that $\mathrm{PBF}$ would make a systemic change at country level possible only if the strategy nicely fits within the country's wider UHC agenda. We therefore advanced our collective learning activities towards views of alignment. That evolution was facilitated by close collaboration with other $\mathrm{CoPs}^{17}$ and agencies such as the $\mathrm{WHO},{ }^{18}$ but also by incorporating in our activities both new concepts, such as strategic purchasing, and lessons coming from country experiences.

We believe that country health authorities could benefit from developing learning agendas for UHC. The core idea would be to map what knowledge is required for the next steps of the progression towards UHC and ensure that these gaps are addressed. Participatory development of the UHC agenda itself would help national authorities to have an extended view on who already does what. It would inform them more deeply on what evidence is still needed to progress towards UHC and what are the learning capacities to strengthen. This approach has the potential to kick start learning for UHC, reduce gaps between knowledge, policy, practice and results, avoid duplication of efforts and at the same time, consolidate the national knowledge ecosystem.

\section{Embrace the 'learning system' vision}

We see the LO concept as a powerful framework to assess the dynamics of health systems and inspire possible action for consolidating systemic learning for UHC. ${ }^{11}{ }^{19}$ A literature review carried out by some of us revealed there is a growing stream of research going into dynamic systems; yet such research still mainly covers situations in highincome countries. ${ }^{20}$ We, like others, ${ }^{21}$ we recommend more investment in this area in low- and middle-income countries (LMICs).

A salient and repeated observation relates to the central role of supportive leadership at the national level. ${ }^{15} 19$ To some extent, the LO logic clashes with the bureaucratic logic which prevails in many public administrations. Without official backing, to institutionalise new learning processes and transform the overall organisational culture will be very tough. A programme of action-research we developed in Morocco taught us that transformative undertakings can easily be compromised by leadership changes. Leaders can contribute to a culture more open to learning through their own decisions (eg, encouraging their subordinates to participate to learning activities), through their mentoring, but also by questioning their own management style.

\section{Value different sources of learning and types of knowledge}

We wish to stress that 'learning for UHC' is not subsumed under 'evidence to policy' or any single method for that matter. Health systems research is crucial for health policy but will not answer every policy question. A large part of the knowledge that countries need for UHC will actually spring from their collective aptitude to innovate, reflect and extract lessons from practice. As a community of action, we must acknowledge that learning may emerge from many situations. Dunlop and Radaelli have identified four situations where policy learning can occur. ${ }^{22}$ Partly because of the way 'global health' is structured, today, as far UHC is concerned, most of the attention goes to 'epistemic learning' (international experts telling countries what to do) and to a less extent, 'learning in the shadow of hierarchy' (training and monitoring). We have to reflect on how we could better value and harness the two other occurrences, which are potentially more horizontal. Rare examples of 'reflexive learning' for UHC are the National Health Assembly in Thailand ${ }^{23}$ and the societal dialogue in Tunisia (http://www.hiwarsaha.tn/). Building national coalitions is central to UHC and health financing policies. ${ }^{24}$ Yet, so far, few really paid attention to the 'learning through bargaining' generated at the level of decision-makers and national UHC 'champions', let alone learning which really starts in communities.

We must also place more value on multiple forms of knowledge. To this end, Freeman and Sturdy's view of knowledge as existing in 'three states' in policies is particularly helpful. ${ }^{25}$ They identify embodied, inscribed and enacted knowledge. 'Inscribing knowledge' (eg, in reports, scientific papers, guidelines, blogposts) is crucial, but it cannot be the only strategy for the UHC agenda. We have to pay far more attention to the actual processes through which knowledge is shared, contextualised, enacted and embodied. For UHC, we will need evidence, repertoires of practices, but also a large supportive 'crowds' of experts and actors ${ }^{26}$-our experience with the CoPs was proof that many knowledge holders are eager to join and collaborate. To mobilise them, we need platforms. We also have to make better 
use of collective intelligence techniques, develop facilitation skills at national and international levels, and pay attention to individuals' intrinsic and extrinsic sources of motivation to participate to learning activities. We need also to understand better how new knowledge gets adopted and enacted into policies and policy implementation. More research in this field will be strategic.

\section{Acknowledge the full set of mechanisms for knowledge management}

Because knowledge for UHC takes on multiple forms, we need to make the best use of the full spectrum of mechanisms available for knowledge production and transfer. Evidence to policy, training, study tours, think-tank guidance, technical assistance, CoPs, networks, innovation platforms, ${ }^{27}$ and even 'ready-made solutions' are all possible routes, each with their pros and cons. Ideally, we should move from the current model where ministries of health are seen as 'recipients' towards a system where ministries of health, as LO, proactively solicit the set of mechanisms and actors, according to their specific needs.

Moving to this situation will take some time. Some weaknesses (eg, bureaucratic culture, limited quantitative data literacy or low practice of new learning mechanisms) seem to prevail across many countries. Although they will not solve all the constraints and we must be cautious with existing possible dominance by Northern actors, ${ }^{28}$ there is room for some international programme promoting a broader approach to learning not only focused on UHC technical issues. For the transfer of the 'soft skills' useful for the UHC agenda, part of the solution could come from joint international action by groups or networks valuing peer-to-peer exchange, such as $\mathrm{P} 4 \mathrm{H}$ (https:// p4h.world/en/), the Health Systems Governance Collaborative (https://hsgovcollab.org/), the Joint Learning Network for UHC (http://www.jointlearningnetwork. org/) and the CoPs. Future efforts should also go into better anchoring (including with funding) the coordination and facilitation of these initiatives in LMICs, as it was, for instance, successfully done for the Emerging Voices for Global Health (https://www.ev4gh.net/).

\section{Invest in national learning capacities}

Learning processes and capacities are present in every country. ${ }^{11}$ Yet, most countries still miss a coherent national knowledge ecosystem: a permanent, dynamic and complementary system of actors and individuals, fully or partly, dedicated to learning for UHC. The example of Thailand shows how having this capacity at national level pays off. ${ }^{29}{ }^{30}$ Even in LICs, much can be done. For instance, the health system research capacity developed in Burkina Faso could be a source of inspiration for many. ${ }^{1131}$

Building such ecosystems takes time. There is no one single route. Our experience supports the notion of the need for diverse approaches. Plurality of opportunities and processes are beneficial to learning. Health authorities could sometimes be more open to new processes (eg, encourage staff to attend webinars, organise lunch seminars), but also be stricter on existing ones (eg, request participants of a study tour to share what they learnt on a blog or the intranet; institutionalise and systematise the guidance to be provided by national research institutions).

Learning is fed by our curiosity, can benefit from some serendipity, but for some matters, institutionalised mechanisms and pathways are required. Countries should prioritise their efforts according to the most urgent operational demands in their systems. For instance, for many LICs, a priority may be to use their routine health information system more robustly. ${ }^{32}$ In our professional practices, we have all observed that routine data generated by health financing schemes are underused. We are still far from so-called 'strategic purchasing, ${ }^{33}$ For countries transitioning out of aid, it is time to establish domestic capacities for health technology assessment and priority setting, including by setting up dedicated entities and procedures for defining benefit packages. ${ }^{34}$ The International Decision Support Initiative (https://www.idsihealth.org/) and HTAsiaLink are good examples of how international collaboration can accelerate consolidation of national knowledge capacities. ${ }^{35} 36$ The latest initiative in this area is the WHO Decide platform (decidehealth. world).

Whatever the context, development partners can and should invest in national knowledge ecosystems, for instance by soliciting national actors, academia, consultants for studies, surveys and evaluations. Our experience shows that this is possible, even in fragile settings and other challenged environments.

\section{CONCLUSION}

Systemic learning can be an inspiring collective endeavour at international and national levels. It constitutes the spine of health system strengthening and advancing the UHC agendas. In many countries, there may still be a need for strengthening almost all the components of knowledge management (production, storage, sharing and enactment). Our group proposes, however, to focus action at three levels first.

1. We have to relocate learning within the "practice arena': our efforts must move from delivering UHC 'knowledge products' to strengthening systemic learning processes and capacities at country level. Ministries of health are invited to embrace a learning perspective much more explicitly. This requires proactive leadership, both locally and at global level.

2. There is a need to support growing a critical mass of actors sustaining and facilitating various learning processes, at national, regional and global level. These actors will have to acknowledge the complex nature of learning and the fact that knowledge relevant for advancing UHC includes scientific evidence and traditional 'evidence for policy' approaches but goes also well beyond. 
3. Collectively, we have to promote a deep transformation of the culture within health systems, around systems' administrations in particular. The introduction of new knowledge management strategies can serve as eye openers-the willingness to change practices will come from the observation that there are superior alternatives.

We are excited by the wide range of possibilities opening up. And of course, all this new learning effort should itself be the subject of ... learning.

\author{
Author affiliations \\ ${ }^{1}$ Collective Horizon, Lier, Belgium \\ ${ }^{2}$ World Health Organization, Rabat, Morocco \\ ${ }^{3}$ Department of Public Health, University Joseph Ki-Zerbo,Health Sciences Training \\ and Research Unit, Ouagadougou, Burkina Faso \\ ${ }^{4}$ Heidelberg Institute of Global Health, Medical Faculty and University Hospital, \\ Heidelberg University, Heidelberg, Germany \\ ${ }^{5}$ Department of Public Health, Institute of Tropical Medicine, Antwerp, Belgium \\ ${ }^{6}$ Collective Horizon, Rabat, Morocco \\ ${ }^{7}$ Ecole Nationale de Santé Publique, Rabat, Morocco \\ ${ }^{8}$ Public Health, Centre de recherche en Reproduction Humaine et en Démographie, \\ Cotonou, Benin \\ ${ }^{9}$ Collective Horizon, New Delhi, India \\ ${ }^{10}$ Community Health Community of Practice, New Delhi, India \\ ${ }^{11}$ UNICEF, New York, NY, USA \\ ${ }^{12}$ World Health Organization, Geneva, Switzerland \\ ${ }^{13}$ Results for Development, Geneva, Switzerland \\ ${ }^{14}$ Collective Horizon, Yaounde, Cameroon \\ ${ }^{15}$ Centre National de Formation et de Recherche en Santé Rurale de Maferinyah, \\ Forécariah, Guinea \\ ${ }^{16}$ Médecine Sociale et Préventive, Université de Montréal, Ecole de Sante Publique, \\ Montreal, Quebec, Canada \\ ${ }^{17}$ Collective Horizon, Montreal, Québec, Canada \\ ${ }^{18}$ Collective Horizon, Amsterdam, Netherlands
}

Twitter Joël Arthur Kiendrébéogo @jarthurk, Jean-Paul Dossou @jdossou80 and Isidore Sieleunou @isieleunou

Acknowledgements This paper is partly based on insights from participants of a 'Learning for UHC' meeting convened in Antwerp in October 2018. We are also grateful to the thousands of experts who contributed to our CoPs. Their enthusiasm is a major source of motivation. We thank NORAD, UNICEF, Belgium and France and other financial partners who helped us to implement this ambitious learning and action programme over nearly a decade.

Contributors All the authors have actively contributed to at least one of the knowledge management activities reported in this practice paper. BM authored the first version of the paper summarising the collective experience. Other co-authors contributed with comments. Editing was finalised by GvH and AGK.

Funding The authors have not declared a specific grant for this research from any funding agency in the public, commercial or not-for-profit sectors.

Competing interests BM holds minority shares in Blue Square, a firm developing software solutions for health systems, including for PBF programmes. Other authors have no conflict of interest.

\section{Patient consent for publication Not required.}

Provenance and peer review Not commissioned; externally peer reviewed.

Data availability statement There are no data in this work.

Open access This is an open access article distributed in accordance with the Creative Commons Attribution Non Commercial (CC BY-NC 4.0) license, which permits others to distribute, remix, adapt, build upon this work non-commercially, and license their derivative works on different terms, provided the original work is properly cited, appropriate credit is given, any changes made indicated, and the use is non-commercial. See: http://creativecommons.org/licenses/by-nc/4.0/.

\section{ORCID iDs}

Bruno Meessen http://orcid.org/0000-0002-0359-8621
Jean-Paul Dossou http://orcid.org/0000-0003-1681-2604

\section{REFERENCES}

1. United Nations General Assembly. Political declaration of the highlevel meeting on universal health coverage, 2019.

2. Wenger E, McDermott R, Snyder WM. A guide to managing knowledge: cultivating communities of practice. Boston: Harvard Business School Press, 2002.

3. Revans R. ABC of action learning. London: Routledge, 2017.

4. Ries E. The lean startup. New York: Crown Business, 2011.

5. Gautier L, Tosun J, De Allegri M, et al. How do diffusion entrepreneurs spread policies? Insights from performance-based financing in Sub-Saharan Africa. World Dev 2018;110:160-75.

6. Meessen B, Hercot D, Noirhomme M, et al. Removing user fees in the health sector: a review of policy processes in six sub-Saharan African countries. Health Policy Plan 2011;26:ii16-29.

7. Meessen B, Kouanda S, Musango L, et al. Communities of practice: the missing link for knowledge management on implementation issues in low-income countries? Trop Med Int Health 2011;16:1007-14.

8. Meessen B, Malanda B, Community of Practice "Health Service Delivery". No universal health coverage without strong local health systems. Bull World Health Organ 2014;92:78-78A.

9. Kelley A, Sieleunou I, Gashubije L, et al. Une vue d'hélicoptère: cartographie des régimes de financement de la santé dans 12 pays d'Afrique Francophone. Communauté de Pratique Accès Financier aux services de Santé et Communauté de Pratique Financement Basé sur la Performance, 2014.

10. Richard F, Antony M, Witter S, et al. Fee exemption for maternal care in sub-Saharan Africa: a review of 11 countries and lessons for the region. Global Health Governance 2013;4:1-20.

11. Akhnif E, Kiendrebeogo JA, Idrissi Azouzzi A, et al. Are our 'UHC systems' learning systems? Piloting an assessment tool and process in six African countries. Health Res Policy Syst 2018;16.

12. Bertone MP, Meessen B, Clarysse G, et al. Assessing communities of practice in health policy: a conceptual framework as a first step towards empirical research. Health Res Policy Sys 2013;11.

13. Garvin DA. Learning in action: a guide to putting the learning organization to work. Boston: Harvard Business School Press, 2000.

14. Millimouno TM, Sidibé S, Delamou A, et al. Evaluation of the maternal deaths surveillance and response system at the health district level in Guinea in 2017 through digital communication tools. Reprod Health 2019;16.

15. Keugoung B, Bello K, Millimouno TM, et al. Mobilizing health district management teams through digital tools: lessons from the District.Team initiative in Benin and guinea using an action research methodology. Under submission.

16. Wikipedia. Collective intelligence, 2019. Available: https://en. wikipedia.org/wiki/Collective_intelligence [Accessed 15 Nov 2019].

17. PBF CoP, E-Med CoP Médicaments, CoP Hub RDC. Financement basé sur la performance et système national d'approvisionnement en médicaments essentiels. Kinshasa: RDC, 2016.

18. Mathauer I. Strategic purchasing: an emerging agenda for UHC Africa, 2016. Health financing in Africa: Le Blog. Available: http:// www.healthfinancingafrica.org/home/strategic-purchasing-anemerging-agenda-for-uhc-in-africa [Accessed 15 Nov 2019].

19. Akhnif E, Macq J, Meessen B. The place of learning in a universal health coverage health policy process: the case of the RAMED policy in Morocco. Health Res Policy Sys 2019;17.

20. Akhnif E, Macq J, Idrissi Fakhreddine MO, et al. Scoping literature review on the Learning Organisation concept as applied to the health system. Health Res Policy Sys 2017;15.

21. Naimoli JF, Saxena S. Realizing their potential to become learning organizations to foster health system resilience: opportunities and challenges for health ministries in low- and middle-income countries. Health Policy Plan 2018;33:1083-95.

22. Dunlop CA, Radaelli CM. Systematising policy learning: from monolith to dimensions. Polit Stud 2013;61:599-619.

23. Rajan D, Mathurapote N, Putthasri W, et al. Institutionalising participatory health governance: lessons from nine years of the National Health Assembly model in Thailand. BMJ Glob Health 2019;4.

24. Kiendrébéogo JA, Meessen B. Ownership of health financing policies in low-income countries: a journey with more than one pathway. BMJ Glob Health 2019;4:e001762.

25. Freeman R, Sturdy S. Knowledge in policy: embodied, inscribed and enacted. Bristol: Policy Press, 2015.

26. Heimans J, Timms H. Understanding "New Power". Harvard Business Review 2014;92:48-56. 
27. Bailie J, Cunningham FC, Bainbridge RG, et al. Comparing and contrasting 'innovation platforms' with other forms of professional networks for strengthening primary healthcare systems for Indigenous Australians. BMJ Glob Health 2018;3:e000683.

28. Abimbola $S$. The foreign gaze: authorship in academic global health. BMJ Glob Health 2019;4:e002068.

29. Harris J. "Developmental capture" of the state: explaining Thailand's universal coverage policy. J Health Polit Policy Law 2015;40:165-93.

30. Teerawattananon Y, Tantivess S, Yothasamut J, et al. Historical development of health technology assessment in Thailand. Int $J$ Technol Assess Health Care 2009;25:241-52.

31. Defor S, Kwamie A, Agyepong IA. Understanding the state of health policy and systems research in West Africa and capacity strengthening needs: Scoping of peer-reviewed publications trends and patterns 1990-2015. Health Res Policy Sys 2017;15.

32. Touré C, Keugoung B, Dossou JP, et al. From health information systems to collective intelligence : Refocusing the health district on the population using ICT. Regional workshop of the community of practice "Health service delivery". Cotonou, 16. Cotonou: Health Service Delivery CoP, 2016.

33. Mathauer I, Dale E, Jowett M, et al. Purchasing health services for universal health coverage: how to make it more strategic. Geneva: WHO, 2019.

34. Glassman A, Giedon U, Smith PC. What's in, what's out? Designing benefits for universal health coverage. Washington DC: Center for Global Development, 2017.

35. Teerawattananon Y, Luz K, Yothasmutra C, et al. Historical development of the HTAsiaLink network and its key determinants of success. Int J Technol Assess Health Care 2018;34:260-6.

36. Tantivess S, Chalkidou K, Tritasavit N, et al. Health technology assessment capacity development in low- and middle-income countries: experiences from the International units of HITAP and NICE. F1000Res 2017;6 